\title{
Cruzamentos Urbanos na Poesia Portuguesa Recente
}

\author{
IDA Alves \\ Universidade Federal Fluminense
}

RESUMO: A PARTIR DE ESTUDO BREVE DA PRODUÇÃO DE TRÊS POETAS PORTUGUESES CONTEMPORÂNEOS, RUI PIRES CABRAL, CARLOS BESSA E MANUEL DE FREITAS, BUSCA-SE INDICAR A PRODUTIVIDADE DO TEMA URBANO E A CONVERGÊNCIA DE EXPERIÊNCIAS DA VISUALIDADE E DO ESPAÇO DA CIDADE A CONSTITUIR UM DISCURSO ELEGÍACO NA LÍRICA PORTUGUESA MAIS RECENTE. DESENVOLVE-SE REFLEXÃO SOBRE A RELAÇÃO POESIA E PAISAGEM, A PARTIR DE UMA FUNDAMENTAÇÃO TEÓRICO-CRÍTICA QUE ABORDA A PAISAGEM COMO CONSTRUÇÃO CULTURAL CAPAZ DE EXPRESSAR DE MANEIRA QUESTIONADORA A RELAÇÃO ENTRE SUJEITO, MUNDO E PALAVRA.

ABSTRACT: FROM A BRIEF STUDY OF THE PRODUCTION OF THREE CONTEMPORARY PORTUGUESE POETS, RUI PIRES CABRAL, CARLOS BESSA AND MANUEL DE FREITAS, WE STRIVE FOR SHOWING THE PRODUCTIVITY OF THE URBAN THEME AND THE CONVERGENCE OF EXPERIENCES OF VISUALITY AND THE SPACE OF CITY BUILDING A ELEGIAC SPEECH IN THE MOST RECENT PORTUGUESE LYRIC. IT IS DEVELOPED A REFLECTION ABOUT THE RELATION BETWEEN POETRY AND LANDSCAPE, FROM A THEORIC-CRITIC FUNDAMENTATION THAT DEALS WITH THE LADSCAPE AS CULTURAL BUILDING ABLE TO EXPRESS IN A QUESTIONING MANNER THE RELATION BETWEEN SUBJECT, WORLD AND WORD.

PALAVRAS-CHAVE: POESIA PORTUGUESA CONTEMPORÂNEA - VISUALIDADE - PAISAGEM — LIRISMO URBANO - CRÍTICA DE POESIA - ELEGIA.

KEYWORDS: CONTEMPORARY PORTUGUESES POETRY - VISUALITY - LANDSCAPE URBAN LYRISM - POETRY CRITICISM - ELEGY. 
m Portugal, com inegável tradição poética, a poesia foi sempre, como escreveu o poeta e crítico Gastão Cruz, "talvez a mais moderna das artes. Ou seja, a mais obstinada nas suas buscas, a mais inquieta na organização do seu discurso."(CRUZ, 1999, p. 212). Mesmo agora na contemporaneidade, em que se discute tanto a ausência de leitores de poesia ou a possível ultrapassagem do texto impresso por novas mídias, a produção lírica em Portugal apresenta vitalidade digna de nota, com a convivência intensa entre nomes mais do que referenciais dessa produção e novíssimos poetas que vêm a publico dizer a sua palavra, ainda que em tiragens pequenas e em editoras jovens.

É nessa escrita mais recente, considerando o período dos anos noventa até agora, que desejamos destacar a força de um tema muito sintomático das tensões e problemas da sociedade atual. Trata-se da vida urbana no que tem de mais radical em termos de embates existenciais e sociais vividos por sujeitos que se confrontam com novas experiências do espaço e do tempo. Poéticas assumidamente espaciais, e em relação a isso lembremos outro fundamental crítico português de poesia, Eduardo Prado Coelho, defendendo o estatuto topológico do autor ${ }^{1}$, o sujeito lírico que nelas se configura tem na visão o seu mais agudo sentido de percepção do mundo, percorrendo ruas de grandes e pequenas cidades, vilas, seus jardins e praças, ocultando-se em prédios e cafés, observando gestos citadinos que marcam o cotidiano e revelam suas pequenas histórias diárias, na realização do movimento de que fala Merleau-Ponty: "O olho é aquilo que foi comovido por um certo impacto do mundo e que o restitui ao visível pelos traços da mão.” (MERLEAU-PONTY, 1997, p.263)

Um contraste muito significativo nessas poéticas efetiva-se na relação entre natureza e cidade ${ }^{2}$, numa retomada crítica da tradição pastoral ${ }^{3}$ em torno da perda da paisagem natural e a inevitabilidade da realidade acentuadamente

1 “[...] o estatuto do autor no processo de produção literária não é um estatuto psicológico (uma entidade psíquica unificada), mas um estatuto topológico (um lugar onde e donde). COELHO, 1972, p. 299.

2 Num clássico dos estudos sobre campo e cidade, Raymond Williams, O campo e a cidade (tradução brasileira de 1990), afirma algo que vem orientando nossos estudos sobre o espaço urbano: "Pois a cidade não é apenas, dentro dessa perspectiva, uma forma da vida moderna: é a consciência física de uma consciência moderna decisiva.” (p. 323).

3 Afirma Greg Garrard, em Ecocrítica (trad. Bras. 2006), p. 55: "Desde as reações poéticas do movimento do romantismo à Revolução Industrial, a pastoral tem moldado de forma decisiva nossas contribuições da natureza. [...] Nenhum outro tropo está tão profundamente arraigado na cultura ocidental, nem é tão profundamente problemático para o ambientalismo." 
urbana, crítica que marca e reflete os impasses de uma subjetividade que se sente mal situada. Experiencia-se o estranhamento e o desencontro ${ }^{4}$ frente à realidade das cidades transformadas velozmente, com consequentes e fundas perdas de memória espacial e afetiva para o sujeito que as vivencia.

No recorte de tempo já indicado, alguns poetas portugueses certamente se destacam ao evidenciarem de forma recorrente essas questões. Reunimos, nesta reflexão, somente três nomes, sem que isso signifique uma inútil vontade unificadora de grupos ou movimentos, mas apenas o reconhecimento de gestos de leitura que demarcam determinados espaços de escrita, possíveis partilhas, certos cruzamentos urbanos. Destacamos, assim, jovens poetas ou nem tanto (já ultrapassaram os 30 anos), mas certamente poetas recentes que começaram a publicar e a expor seus trabalhos poéticos a partir dos anos 90, como Rui Pires Cabral (primeiro livro de poesia em 1994), Carlos Bessa (em 1995) e Manuel de Freitas (em 2000), e hoje são vozes com assinalável recepção de leitura e de crítica. Diferentes entre si, manifestam entretanto, de maneira dialogante, uma forte subjetividade urbana e uma relação oscilante entre atração e repúdio pela cidade e consequências de sua expansão. Interessa-nos seguir como esses poetas percebem o espaço à sua volta e como essa percepção é uma construção cultural indiciadora de uma visão crítica sobre o mundo que os constitui como sujeitos. Tais percepções se efetivam numa organização imagética que nomeamos como paisagem, seguindo a perspectiva analítica de Michel Collot em relação à poesia francesa contemporânea nos seus muitos estudos sobre poesia e paisagem", a partir da "crítica temática”defendida por Jean-Pierre Richards: “[...] la notion de paysage peutelle être utilisé pour désigner l'ensemble des choix sensoriels révélateurs des grandes atitudes existentielles d'un auteur." (COLLOT, 1995, p.218)

Nessa tríade de poetas portugueses, a paisagem é uma questão provocativa, principalmente na observação de sua ausência ou na sua desfiguração pelo horizonte de cimento ou pela falta de estabilidade, já que as imagens revelam apenas o efêmero, o passageiro, o transitório. Em seus poemas, constatamos

4 Utilizamos aqui categorias exploradas por Ana Fani Alessandri Carlos em seu estudo Espaco-tempo na metrópole, Contexto, 2001, ao discutir a "reprodução do espaço social". Cf. Capítulo "A dialética do estranhamento-reconhecimento", p. 328 e seguintes.

5 Ver especialmente COLLOT, 2005. Nas referências bibliográficas indicamos algumas de suas principais obras. 
uma escrita problematizadora do tempo presente, a nostalgia reatualizada da pastoral, delineando-se espaços fechados e opressivos na passagem de uma tradição bucólica para a realidade da cidade moderna e já agora pós-moderna (passe o termo e suas indefinições...).

No fundo, por trás de campos e cidades, fala-se de um núcleo teórico muito atual: a paisagem como estrutura de sentido e como esta se tem tornado, especialmente no contexto cultural europeu, um tema de atenção maior, discussão e pesquisa. $\mathrm{O}$ acirramento de debates e ações ecológicas decorrentes da ameaça cada vez mais visível de destruição dos recursos naturais da Terra fomentam esse interesse, mas, mais do que isso, acentua-se a necessidade de refletir sobre modos de habitar o mundo e de habitar a arte, de viver numa cultura. É nessa direção, por exemplo, que se desenvolvem há cerca de uma década os estudos do já referido pesquisador Michel Collot ${ }^{6}$ sobre poesia e paisagem, considerando a segunda uma organização simbólica que reflete com muita pertinência no âmbito do literário os impasses da cultura contemporânea.

Também no panorama da poesia portuguesa mais recente reencontramos a questão da paisagem. Como sabemos, sempre foram recorrentes nessa produção duas contruções imagéticas fortes: a atração pelo mar, como ânsia do horizonte, da outridade e a posse da terra como vontade de enraizamento. Ao longo do século XX e especialmente nas suas últimas décadas, porém, deslocaram-se de maneira mais radical esses dois espaços imagéticos em prol da expressão do urbano, afirmando-se novas práticas espaciais. Frente a esse panorama, a ausência de paisagens naturais ou a certeza de sua degradação tornaram-se indicações constantes na poesia mais recente, delineando-se o domínio cada vez mais sufocante de espaços fechados em que se refugiam os sujeitos em busca de um lugar mínimo de observação do mundo: os cafés, os bares, as tascas, os quartos de pensões ou de hotéis, os carros, os comboios, figurando-se sentimentos de indiferença, de desencontro, de estranhamento. Para o olhar que se volta para fora, há uma constatação irremediável: a ocupação do espaço pelos restos do consumismo, pelo lixo da cidade, metáfora capital da escrita deste tempo marcado pelas ruínas da história e da memória.

6 É professor de literatura francesa da Universidade Paris III. Especialista de poesia moderna e contemporânea, lidera equipe de investigação sobre poesia e paisagem. 
Em decorrência desse quadro de degradação e perda, um tom muito presente nessa escrita é o elegíaco: o sujeito lírico manifesta o desencanto e o sentimento de desabrigo a envolver a memória afetiva pelo confronto violento com os não-lugares que abundam na supermodernidade ${ }^{7}$. A elegia, forma poética de grande tradição na poesia lírica ocidental, foi atravessando os séculos e se adaptando a novos modos de percepção e de vivência das transformações do mundo. Na elegia moderna, destacam-se, por exemplo, os poemas de Rainer-Maria Rilke, Elégies à Duino, meditação sobre a precariedade do ser. Sobre esses poemas, escreve o ensaísta Jean-Michel Maulpoix: "Não se trata dessa vez de um canto fúnebre ou melancólico, mas de uma verdadeira abertura da palavra à angústia [...] O poeta interroga. Ele se coloca como aquele que questiona, antes de ser aquele que celebra ou que se lamenta." Seguindo o raciocínio de Maulpoix, podemos dizer que a poesia moderna renova a elegia exatamente tornando-a "le poème humain, par excellence", na medida em que traz à tona a criatura "na sua precariedade, na sua insuficiência, na sua derrota, e trabalha por reinscrevê-la no mundo com plena consciência de seu divórcio com ele. A elegia é por excelência o poema do ser que enfrenta [...]"9

E é exatamente por essa perspectiva que seguimos na poesia portuguesa mais recente um discurso elegíaco que pode ser considerado como sintoma de uma experiência física, espacial e temporal tensa, de não integração ao mundo, e por isso palavra lutuosa de deriva interior e exterior. Os novos poetas, oriundos já de realidades frontalmente urbanas, formados a partir de relações outras com a espacialidade e temporalidade, tornam sua escrita uma interrogação sobre como existir no contemporâneo tão marcado pelo efêmero, pela velocidade, pela indiferenciação e pela dominante transformação mercadológica de tudo.Nesse sentido, há também nesses poetas um senso agudo de ironia que impede o que poderia se tornar uma adesão excessiva ao lirismo metafísico para reforçar, com distanciamento crítico, a aproximação do concreto, do aqui e agora que é o poema e que é a vida. Representam, de

7 Seguimos aqui AUGÉ, 6a.ed, 2007.

8 "Il ne s'agit pas cette fois d'un chant funèbre ou mélancolique, mais d'une véritable ouverture de la parole à l'angoisse. [...] Le poète interroge. Il se pose comme celui que questionne, avant d'être celui qui célèbre ou qui déplore". MAUPOIX (2000: 212)

9 "dans sa précarité, son insuffisance, sa défaite, et travaille à la réinscrire dans le monde em pleine conscience de son divorce d'avec lui. L'élégie est par excellence le poème de l'être qui fait face [...]" (MAULPOIX, 2000, p. 216). 
certa maneira, a continuidade daquele poeta sem aura baudelairiano pondo em suspeita a própria poesia ${ }^{10}$, lançando-se no movimento do mundo. Trata-se então de falar de elegia e de paisagem como configurações de subjetividades outras, híbridas, deslocadas, fragmentadas e precárias. Cria-se igualmente uma relação diversa com o leitor de poesia, esse outro sujeito que segue pelas ruas, acotovelando-se nas multidões cosmopolitas, entregue às dissonâncias do cotidiano, ou, mais recentemente, entregue a uma "topologia eletrônica", que aboliu a dimensão física criando uma transitividade absoluta, um continuum insuportável, como discute Paul Virilio ${ }^{11}$.

Frente a esse contexto traçado a grosso modo, os poetas aqui chamados respondem de maneira convergente, dando voz a sujeitos líricos errantes e insatisfeitos. O primeiro que destacamos, Rui Pires Cabral, já apresenta nos títulos de seus livros essa visão paisagística que marca uma parte da produção poética portuguesa: Geografia das estações (1994), A super-realidade (1995), Música antológica \& onze cidades (1997), Praças e Quintais (2003), Longe da aldeia (2005), Capitais da solidão (2006), títulos que apontam uma subjetividade desencantada e deslocada em meio à concretude do mundo.

É uma poética em que o EU se diz na relação interrompida ou falhada com o TU (o outro, que tanto pode figurar a mulher amada, como a memória dos que se foram, como a escrita). No tom prosaico, discursivo, que vem a caracterizar muito dessa poesia mais atual, narram-se histórias de personas desencontradas, descrentes e solitárias. O tom é de ironia mal disfarçada a acentuar o olhar melancólico: "[...] Um ano inteiro não será suficiente / para tudo o que não nos acontece.", lemos ao final do poema "Lost weekend" (1997, p.10). A cidade é o espaço em que se encenam essas histórias e onde circulam predominantemente esses corpos mal situados. O levantamento lexical e imagético ratificaria com facilidade essa negatividade e o tom elegíaco que atravessa a sua escrita: "Eu e tu, que desculpa ainda nos justifica? / A cidade não foi feita para as nossas pretensões,/ está apenas alastrada por dentro de nós, crispação / de pedras e espinhos no laço desfeito entre as veias. / (idem, p.10). Com frequência, nesses poemas, as janelas estão fechadas ou não dão

10 Cf. o estudo de Maulpoix intitulado "Le deuil dy lyrisme", sobre a elegia contemporânea, publicado em La poésie comme l'amour (1998).

11 Cf. VIRILIO, Paul. 2005. 
para lugar algum; também a paisagem se ausenta ou se desfigura atravessada pelas paredes, muros, cimento. O olhar do sujeito lírico é o espaço de concentração de todas as imagens e a ponte instável entre o imaginário e o real, acentuando-se o movimento contínuo entre o interior e o exterior.

Uma casa foi inventada para sustentar o espaço

sobre aquela praça, obrigava aos caminhos que tomavas,

trazia a claridade em todas as hastes. Por quem esperavas

se a paisagem estava vazia?

$[\ldots]$

[...] Tu contavas quantos obstáculos os dias traziam

à terra, eram pequenas armadilhas para os teus movimentos.

E desde o primeiro, todos os corpos ganharam a sua distância

como barcos a que não podias dar sentido.

(1997, p.24)

É, aliás, bastante interessante o processo de cruzamento entre a interioridade do sujeito e a exterioridade do mundo. Em diversos poemas esse processo é o foco de atenção do gesto lírico, tornando ainda mais aguda a desfiguração do sujeito e da paisagem dominantemente urbana. No poema "China Doll"12 lemos:

Eu ia na passadeira com um propósito mas

a gravata de um homem atirou-me para o coração

do abismo. Uma insuspeitada gravata de seda

com pintas discretas, o catalizador

da vertigem. Aquilo que o vento levantava

na avenida era uma espécie

de música, um barulho de sinos remoto

12 O título do poema é também um cruzamento interessante de referências culturais, musicais, linguísticas que não abordaremos aqui. 
e descompassado, viam-se algumas flores

a entrar na boca do esgoto como se fosse ali

a casa delas. E sem deixar eco qualquer coisa ruía

nas fachadas, o próprio oxigénio era nesse instante

como uma língua estrangeira. Eu sentia na garganta os tambores

do sangue e os prédios enfadonhos pulsavam

na taquicardia, caíam em desamparo

para a cova do meu peito. Do outro lado da rua

um sinal de trânsito foi a minha âncora.

(1997, p. 31)

A cidade, nessa poética, é espaço ambíguo de repúdio e de atração. Por um lado, o cotidiano urbano é a realidade inevitável desses sujeitos contemporâneos, que se querem cosmopolitas; por outro, há um sentimento doloroso de existência, de opressão, de falha, de estranhamento frente a uma vida cada vez mais sem sentido, mais e mais afastada de uma memória afetiva rica marcada pelo domínio corporal de espaços plenamente habitados e percorridos. Nesse quadro, os poetas são sujeitos que inscrevem no corpo da escrita a fragmentação urbana, a deambulação pelas ruas indiferentes e o aprisionamento em quartos alheios: "Quantas cidades nos acolheram na sua pressentida, / inconsolável solidão? [...] Aqui dentro as persianas / já não fecham como deve ser e nos calendários a natureza / é uma inócua mentira." (2003: p. 27), ou "[...] Saíamos para a rua com a noite / adiantada, observávamos o trânsito das tribos / no seu habitat natural. E como eram largas as horas / naqueles redutos secretos, como nos convinha a turbulência / nas esquinas, na Gran Vía onde as chinesas vendiam sandes / de frango e pimento. [...] (2003, p. 39). ${ }^{13}$

Rui Pires Cabral vem, de livro a livro, partilhando com outros poetas de sua faixa etária um mesmo sentimento de "fora do lugar", uma escrita onde se repete o advérbio não, onde se figura uma vida que já começa na ruína e fora

13 Como não lembrar de Cesário Verde "O sentimento dum ocidental" : "Mas se vivemos, os emparedados, / Sem árvores, no vale escuro das muralhas!...” ou de Álvaro de Campos, oprimido em quartos de aluguel? 
de qualquer ordem. Disso fala bem o poema "Fora do lugar", do livro Longe da Aldeia (2005:32)

A dor é uma desordem inimiga das palavras com o silêncio todo fora do lugar. Saberemos tomar um caminho por essa floresta escura? Poderemos sequer recuperar a pequena bússola partida, a caneta e o papel, as nossas certezas de trazer no bolso?

Não nos avisaram contra o medo, não nos disseram que pode chegar a qualquer hora, deslealmente, enquanto o sol dorme na paisagem e as ervas se levantam para receber o Verão. E agora que nos perdemos quase, sem mapa ou sentido que nos sirva, o nosso único guia é o amor dos que nos esperam numa sala branca onde o chão nos falta e não há estações.

Outro poeta contemporâneo, Carlos Bessa ${ }^{14}$, apresenta questões semelhantes em torno da poesia originária de uma vivência urbana rarefeita e distópica. Em "Fala do poeta maldito", poema que encerra seu último livro até o momento, Dezanove maneiras de fazer a mesma pergunta (2007, p. 31), o sujeito lírico traça sua face: "Sou um poeta maldito porque não consigo / que a natureza compareça no que escrevo, / Flor, nuvem, montanha recusam-me, não têm lugar / no glossário com que o meu cérebro trabalha. / Sou um poeta maldito, mimético, de / tradição urbana. E sofro. Porque falho. / Porque não pertenço a nenhum lado. /Entro no automóvel e colapso. [...]

14 Nascido em 1967, publicou em 1995 seu primeiro livro Legendas. Seguem-se Termómetro. Diário (1998), Olhos de morder lembrar e partir (2000), Lançam-se os músculos em brutal oficinal (2000), Em trânsito (2003), Em partes iguais (2004), Dezanove maneira de fazer a mesma pergunta (2007). Desde meados de 1990, passou a viver nos Açores. 
Mas é no livro anterior, Em partes iguais (2004), que vários poemas vão constituindo uma perspectiva elegíaca da escrita poética e um sentido agônico de existência. Também escrita prosaica, descritiva de cenários citadinos, a história que se conta é igualmente de sujeitos desencantados e solitários, questionadores porém do mundo que os cerca na sua vacuidade e artificialidade: "Chuvisca. É quarta-feira. A morte é / tudo o que resta. E eufórico, ris-te. / É possível que os cemitérios sejam / cenários risíveis, como as árvores / de que já quase ninguém sabe o nome.” (p.32). E disso fala, de forma muito bem elaborada, o poema "montras" (36-37), em que o olhar do sujeito lírico acompanha os rostos, os gestos e as palavras dos que partilham o espaço público do café. A descrição detalhada vai elaborando uma cena urbana e constituindo uma pequena narrativa do tempo que os cerca, dando a ver (montras = vitrines) "o mesmo vazio de sempre".

Folheiam o jornal e nada acontece, o cabelo dele continua preto, o dela, louro alvo, pintado, com nuances.

A cerveja, de horas, está morta, azeda. Juntos reparam nas saídas e entradas, com um olhar que se torna insistente se entra alguém que é, pela aparência, urbano. $[. .$.

[...] Há gestos que são tudo, tréguas, desejos, perguntas. Por isso fala do novo apartamento. Ela sublinha, vagarosa, o número da porta e o nome da rua. Momentos depois, o do andar. Um telemóvel começa a tocar e impressiona o excesso de solidão com que todos se sentem o centro das atenções. A loura abre ostensivamente o jornal na página dos anúncios. Sabe que quando o jogo chegar ao fim regressarão as montras, 
a procura desenfreada, o mesmo

vazio de sempre.

Uma relação interessante a se desenvolver em relação a essa poética é que estamos frente a resquícios de um discurso "épico" minado completamente pela contemporaneidade, ou seja, as histórias que se contam, cotidianas, triviais, são restos de uma narrativa coletiva que se repete continuamente, sem glória ou heróis: "Estacionar o carro é amiúde / o último passo de uma batalha. / Gente há que para fugir ao desespero / liga para as informações.[...] Mas talvez o melhor antídoto da raiva / e da falta de razões ainda sejam essas / vozes neutras e profissionais que cumprem / o salário na mais nobre das tarefas, / as da escuta. Embora seja de gente / e como tal resvalem e nos deixem sem / outras lágrimas que as dos filmes que / passam na televisão.” (p.41)

Sob essa perspectiva, a poética de Bessa parece concentrar fortemente certo espírito de aniquilamento, descrédito e vazio muito presente na poesia portuguesa do final do século XX: "A vida, essa sujidade como papel / químico, que deixa nos dedos a comichão / da escrita. [...]" (p.46). Seguindo nela a ausência sintomática da natureza e o predomínio de uma paisagem urbana claustrofóbica, lemos em seus versos também a elegia possível da atualidade: "O passado parece ter perdido / a maior parte das suas funções / pedagógicas, uma ficção entre tantas. $[\ldots] /[\ldots]$ a obsolescência / faz parte do quotidiano, a / sobrevivência assenta no / costume e na memória / as vertigens conduzem as pessoas / aos seus bunkers particulares. / O medo, o medo: a nossa especialidade (casas, prisões, / hospitais). [...]/ [...] a literatura, essa, é isso tudo, a febre moral / de um país onde parece comum / uma mesma vocação para o fracasso. (p.47)

Perseguir a paisagem na poesia auxilia a ver, com acuidade, a problemática relação entre sujeito e mundo a partir de experiências corporais de perda, de degradação ou solidão, por outro, possibilita reconhecer a sobrevida de gestos de singularidade num tempo de massificação e de indiferenciação. Essa preocupação em tornar visíveis histórias privadas e coletivas do cotidiano tem provocado que alguns críticos de poesia portugueses discutam a hipótese de um novo lirismo figurativo ou da experiência, feito de espaços predominantemente urbanos e de um retorno ao biografismo e às emoções, como analisam Joaquim Manuel Magalhães (1981), Fernando Pinto do Amaral (1991) e Rosa 
Martelo (2004). E tais discussões foram especialmente motivadas a partir de atos de escrita de outro poeta, Manuel de Freitas ${ }^{15}$. Sua poética trata de uma subjetividade muito forte que se reflete num espaço degradado e artificial: com a natureza praticamente ausente, dominam os espaços fechados da cidade: os prédios, as lojas, os supermercados e, sobretudo, os pequenos cafés, bares, as tascas, espécies de cavernas reatualizadas em que os homens se abrigam da solidão e do vazio, sem mais verdades que o façam reconhecer o ideal. A poética de Freitas fala da dor de existir: sua narração de mundo é fundamentalmente uma experiência de finitude, de morte, mais acentuada ainda pelo desencontro e pelo cotidiano irrelevante, constituindo uma subjetividade amarga e descrente de qualquer espécie de saída deste mundo-prisão. A realidade contemporânea exigiria um novo lirismo, o lirismo do resto, do imperfeito, do lixo, metáfora fundamental de uma sociedade de consumo e de espetáculo ${ }^{16}$.

Surgido no panorama poético português em meio a uma grande polémica provocada por um prefácio de sua autoria na pequena antologia intitulada Poetas sem Qualidades (2002), sobre a qual já nos detivemos em textos anteriores $^{17}$, seus livros, em geral breves, em edições simples, por vezes, de exíguas tiragens, têm demarcado um lugar outro atento a este tempo e suas marcas mais evidentes: a indiferenciação, a banalização, a mercantilização de tudo, o processo contínuo de arruinamento de valores e matérias. Poética que se afirma longe de qualquer retórica elevada ou de qualquer espécie de sagração da arte poética, sua palavra glosa a morte em muitas variações, fortemente crítica de si própria e da vida, meditação em tom menor da condição humana ordinária.

Por esse viés de compreensão, podemos dizer que temos diante de nós também uma poética elegíaca ${ }^{18}$, na medida em que o tema mais forte é a fi-

15 Em resenha ao último livro (ou plaquette) do poeta, Boa Morte (2008), o conhecido crítico de poesia António Guerreiro afirmou: "[...] julgo poder formular sem grande risco: estamos perante o poeta mais forte da sua geração (e 'geração' refere-se a um período de tempo muito mais longo do que a unidade arbitrária da década.)". (Jornal Expresso, parte Actual, 10 janeiro 2009, p. 28.)

16 Há nisso o diálogo com outro poeta, Joaquim Manuel Magalhães, voz dos anos 70 que se tornou uma espécie de consciência crítica para os jovens poetas que viriam depois. Ver seu livro Dois Crepúculos - Sobre poesia portuguesa actual e outras crónicas, de 1981.

17 Cito apenas o mais recente: ALVES, Ida. Conflito de opiniões na poesia portuguesa: o esterco lirico e o grito do anjo. In: PEDROSA, Celia e ALVES, Ida. 2008, p. 118-132.

18 Explica-nos Jean-Michel Maulpoix: “ Thréne à l'origine, chant funèbre accompagnée de la flûte, l'élégie fait partie des oeuvres d'esprit funéraire, telles que l'Oraison funèbre, l'Épitaphe, le Tombeau 
nitude humana e a certeza de perda e desvalia de tudo frente ao mundo que nos rodeia, tão marcado no presente pelo excesso de técnica, de tecnologias, de informações, de imagens, de artificial vitalidade.

\section{Centro comercial 1}

Agora a morte é diferente, facilitaram-nos o desespero, a angústia tem já ar condicionado. Em vez dos bancos de jardim, por certo demasiado rudes, temos enfim lugares amplos onde apodrecer a miséria simples do corpo.

Que incalculável felicidade a de percorrer galerias de nada tresandando a limpeza e segurança. Aí se abandonam jovens rebanhos sentados sorrindo ao vazio palpável, ou ferozmente no meio dele. Revezam-se - mas quase diríamos que os mesmos ainda, exaustos de contentamento. Demos pois as boas - vindas a esses heróis do betão consagrado. Só eles nos fazem acreditar no advento do romantismo cibernético.

É doce a merda que nos sepulta e o cancro que um dia destes nos matará há-se de ser muito limpo, quase ecológico.

(2000, p. 59)

ou le Tumulus. Elle trouve as place parmi diverses espèces de déplorations. Mais elle tend à se poser elle-même comme la forme da plus pure de la déploration, puisque sa propriété est de bercer la tristesse par le chant." (2000, p.189) 
Com um "cenário" urbano, e alguns títulos de poemas são endereços de bares, o sujeito lírico deambula por ruas de Lisboa, penetrando em espaços alegoricamente mortais: os cafés, os bares ou tabernas, onde a morte se torna visível nos rostos dos frequentadores e no ambiente que os acolhe. Lemos no poema "Praça das Flores n. 5", "Tarde chuvosa de Verão a redimir / o luminoso e opressivo cansaço de Lisboa. / Abrigo-me numa taberna agora sombria / devido ao cinzento súbito do céu.// Dir-se-ia ter nos meus ombros / toda a tristeza do mundo, ainda que / o mundo pouco valha ao pé desta taberna / na tarde molhada da cidade. E contudo / sinto-me estranho como em qualquer lugar, / espião não da casa do amor mas na da / morte quotidianamente vivida. [...]" (2000, p. 31, idem).

Se aceitamos que a superexposição e a ubiquidade ótico-eletrônica domina nosso tempo, como sustenta Paul Virílio (1995: p.14 e passim), acarretando "a crise das referências (éticas, estéticas), a incapacidade de avaliar os acontecimentos em um meio em que as aparências estão contra nós” (p.18), não é difícil compreender como a escrita desidealizada de Manuel de Freitas responde a esse excesso de presença virtual figurando obsessivamente a ausência e a escassez. Sintomaticamente a paisagem natural também se ausenta de seus poemas, e não há qualquer horizonte que não seja o da morte.

Expondo o desabrigo, a solidão e a incomunicabilidade dos corpos, os poemas de Freitas se transformam numa elegia contemporânea, afastada da elegia moderna de Rilke com seu "espaço de abertura máxima da linguagem e do pensamento" 19 , pois a meditação sobre a morte, em sua poética, não é uma questão de linguagem à maneira de Blanchot ou de Agambem $^{20}$, já que sua "língua poética" é provocativamente banal, simples, cotidiana, prosaica, rejeitando a metáfora ou a figuração elevada da linguagem poética. No entanto, essa banalidade e simplicidade estrutural acabam por sustentar um discurso poético conceitualmente alegórico, em que se avolumam as imagens do arruinamento do espaço e do tempo, as tensões existenciais e emotivas, as antíteses e paradoxos. Os poemas tornam-se lápides, configuram-se como espaços fechados de ausência e perda, câmaras mortuárias onde se diz o luto sem solução.

19 Cito MAULPOIX, p. 216.

20 Cf. AGAMBEM, 2006. 


\section{Não vale a pena empurrar o discurso}

até aos nulos e fulgurantes

limites da linguagem. Não vale a pena

nomear o vazio com palavras mais estéreis ainda.

Que pereça sozinho este mundo onde

por descuido regressámos a um corpo

e lhe ensinámos a ruína, os vários

rostos da morte.

$[\ldots]$

Tudo existe mas nada é real, nem sequer o vazio. Digamos adeus

à alma que se nos nega

como uma salsicha sem lata,

deixando o poema esquecido

a um canto de si, liquefeito e atroz.

De nosso só temos a morte,

o que não vale a pena sabermos.

(2001, poema Sinleté)

Sob essa escrita lutuosa revela-se entretanto uma vontade de enfrentar as práticas de convívio cada vez mais artificiais, impessoais e mercadológicas. $\mathrm{O}$ poeta intenta também, em contexto português de tanta tradição lírica, deslocar a poesia do seu lugar aurático, "literário", para o chão das ruas, para as mesas dos bares, para os rostos dos comuns, tornando-a uma provocação, uma forma de dizer "não" aos discursos sedimentados da contemporaneidade.

Assim, fechando o círculo de leitura dessas três poéticas, quisemos demonstrar que parte da poesia portuguesa mais recente evidencia uma opção comum: o olhar sobre o urbano, sobre a vivência citadina e seus impasses, a partir de subjetividades fragmentadas que se vão constituindo no cruzamento com a paisagem dominante de agora, de artificial ou rarefeita natureza: ruas, prédios, esquinas, centro comerciais, tabernas, praças, jardins, lugares públicos e coletivos de solidão e de desencontro. Falar das cidades, ou de seus lugares de rotina cotidiana, nessa produção lírica, é a forma recorrente 
de escrever como a paisagem é hoje muito mais ausência do que presença, configuração de olhares inquietos e insatisfeitos de indivíduos que se afastam, sem possibilidade de retorno, de um horizonte de harmonia e de totalidade, imersos que estão num mundo cada vez mais desfigurado.

\section{Referências Bibliográficas}

AGAMBEN, Giorgio. A linguagem e a morte - um seminário sobre o lugar da negatividade. Belo Horizonte: Editora da UFMG, 2006.

AMARAL, Fernando Pinto do. O mosaico fluido - Modernidade e Pós-modernidade na poesia portuguesa mais recente. Lisboa: Assírio \& Alvim, 1991.

AUGÉ, Marc. Não-lugares, introdução a uma antropologia da supermodernidade. 6a.ed. São Paulo: Papirus, 2007.

CABRAL, Rui Pires. Música antológica \& onze cidades. Lisboa: Presença, 1997. . Praças e quintais. Lisboa: Averno, 2003. . Longe da aldeia. Lisboa: Averno, 2005.

. Capitais da solidão. Vila Real: Teatro de Vila Real, 2006.

. Poemas. Coleção Portugal, 0, 2. Rio de Janeiro: Oficina Raquel, 2007.

CARLOS, Ana Fani Alessandri. Espaço-tempo na metrópole. São Paulo: Contexto, 2001.

COELHO, Eduardo Prado. O reino flutuante. Lisboa: Edições 70, 1972.

COLLOT, Michel et al. (dir.). Paysage et poésie du romantisme à nos jours. Paris: José Corti, 2005.

. La notion de paysage dans la critique thématique. In: .(dir.). Les

enjeux du paysage. Bruxelles: Ousia, 1997.

. La poésie moderne et la structure d'horizon. Paris: PUF, 1989.

. L'borizon fabuleux I (XIX siècle) et II (XX siècle). Paris: José Corti, 1988.

CRUZ, Gastão. A poesia portuguesa hoje. 2a. ed., corr. e aum., Lisboa: Relógio d'Água, 1999. FREITAS, Manuel de. Todos contentes e eu também. Porto: Campo das Letras, 2000. . Os infernos artificiais. Lisboa: Frenesi, 2001.

. Poetas sem qualidades. Lisboa: Averno, 2002.

. Poemas. Coleção Portugal 0, 1. Rio de Janeiro: Oficina Raquel, 2007.

GARRARD, Greg. Ecocritica [trad. Vera Ribeiro]. Brasília: Editora Universidade de Brasília, 2006.

GUERREIRO, António. A arte de ajudar a morrer. In: Jornal 259Expresso [Actual]. Lisboa, 10/01/2009. p.28

MAGALHÃES, Joaquim Manuel. Os dois crepuisculos - sobre poesia portuguesa actual e outras crónicas. Lisboa: A Regra do Jogo, 1981. 
MARTELO, Rosa Maria. Em parte incerta. Estudos de poesia portuguesa moderna e contemporânea. Porto: Campo das Letras, 2004.

MAULPOIX, Jean-Michel. Du lyrisme. 3.ed. Paris: José Corti, 2000

MERLEAU-PONTY, Maurice. O olho e o espírito. In: DUARTE, Rodrigo (org.). O belo autônomo - textos clássicos de estética. Belo Horizonte: Editora UFMG, 1997.

PEDROSA, Celia e ALVES, Ida. Subjetividades em devir - estudos de poesia moderna e contemporânea. Rio de Janeiro: 7Letras, 2008.

RICHARD, Jean-Pierre. Microlectures II - Pages paysages. Paris: Seuil, 1984.

ROGER, A. La théorie du paysage en France 1974-1994. Syssel: Champ Vallon, 1995.

WILLIAMS, Raymond. O campo e a cidade [trad. Paulo Henriques Brito]. São Paulo: Companhia das Letras, 1990.

VIRILIO, Paul. Espaço crítico. Rio de Janeiro: Editora 34, 1993. 